\title{
Intelligent Cuckoo Search Algorithm of PID and Skyhook Controller for Semi-Active Suspension System using Magneto- Rheological Damper
}

\author{
A. H. Mohd Yamin, I. Z. Mat Darus*, N.S. Mohd Nor, M. H. Ab Talib \\ School of Mechanical Engineering, Faculty of Engineering, Universiti Teknologi \\ Malaysia, Johor Bahru, Johor, Malaysia
}

\begin{abstract}
This article introduces the application of the Cuckoo Search (CS) Algorithm to tune Proportional-Integral-Derivative (PID) and Skyhook controller for the semi-active (SA) suspension system further to improve the vehicle's ride comfort and stability. Meanwhile, the PID-CSA and Skyhook-CSA intelligent approaches have been compared to the passive suspension system. The performance of the PID controller and Skyhook controller are optimised by Cuckoo Search (CS) Algorithm, respectively. The system's mean square error (MSE) is defined as the objective function for optimising the proposed controllers. The performance of the proposed PID-CSA and Skyhook-CSA controllers are evaluated with the passive suspension system in the form of body acceleration, body displacement, and tire acceleration. The sinusoidal road profile is set as the disturbance of this system. The percentage improvement for body acceleration and body displacement achieved about $25 \%$ for the PID-CSA controller and 1-4\% for Skyhook-CSA. These simulated results reflect that the proposed controllers outperformed other considered methods to obtain the most effective vehicle stability and ride comfort.
\end{abstract}

Keywords: quarter car model, semi-active (SA) suspension, PID controller, skyhook controller, Cuckoo Search (CS) Algorithm.

${ }^{*}$ For correspondence: intan@utm.my

Received: 23 Nov 2020

Accepted: 15 August 2021

(C) Copyright Yamin. This article is distributed under the terms of the Creative Commons Attribution License, which permits unrestricted use and redistribution provided that the original author and source are credited.

\section{Introduction}

The suspension system has been studied for many years, playing a crucial role in supporting the vehicle's body and reducing body vibration from the road surface. Most of the vehicle dynamics studies focus mainly on the suspension system to achieve vehicle ride efficiency, stability, and handling [1]. The vehicle suspension intends to attenuate the vehicle body's vibration caused by the road surface, to support the vehicle body, and to keep the vehicle occupant in comfort and for vehicle handling [2].

The biggest challenge for suspension systems is that the presence of uncertainties is due to the load's variability once the suspension system structure varies. Due to the varying speed of the vehicle and the changing roughness of the surface, the suspension vibration responds differently to the road. Thus the setting changes throughout the entire running process affecting the spring stiffness and damper ratio. These uncertainties can lead to two problems in the implementation: performance and reliability.

In conventional configuration, the suspension system comprises the three main elements, such as elastic element, damping element, and mechanical element. The coil spring was the elastic element that 
provides a force proportional and contrary to the elongation of the suspension elongation; this part carries the static load. The hydraulic shock absorber, which is the damping element, provides a dissipative force proportional to and opposite to the elongation speed; this part produces a negligible steady-state force but plays a vital role in the suspension's dynamic behaviour. Lastly, a series of mechanical elements bind the sprung mass to the unsprung mass.

The suspension system in the ground vehicle is attached between the vehicle's body and the vehicle's wheels. There are three types of vehicle suspension systems available, such as passive, semi-active (SA), and active systems. The components of suspension depending on the type of suspension system. The semi-active (SA) and active suspension systems incorporated into the passive system would normally promise good stability with respect to the handling and performance of vehicles.

The typical or passive suspension system comprises an element of damper and spring, and it generally contains a restricted ride comfort performance. When the damping is high, the passenger is sometimes best isolated from the minimum-frequency disturbances. Nevertheless, high damping offers low absorption at high frequencies. On the other hand, once the damping value is minimal, the damper offers adequate high-frequency absorption at a low-frequency isolation cost [3]. The restrictions of passive suspension system encouraged the exploration of the active suspension system. Even though the active suspension system is very proficient in damping, it involves very high power consumption, and the cost of production is expensive [4].

The semi-active (SA) suspension system is introduced in vibration control to overcome the weaknesses of passive and active suspension systems. Various researches have been conducted by previous researchers to control the semi-active (SA) suspension with MR damper. These include the utilisation of PID control [5], skyhook control [6], sliding mode control [7], neuro-fuzzy control [8], Takagi-Sugeno Fuzzy Control [9] and ground hook control [10]. However, the deployment of swarm intelligence as the optimisation technique improves the capability of semi-active (SA) system. The research in semi-active with intelligent approaches includes adaptive neural network [11], Particle Swarm Optimisation [12], Firefly algorithm [13], Bayesian optimization [14] and Genetic Algorithm [15].

The primary objective of this paper is to develop and compare both the PID controller and Skyhook controller tuned by Cuckoo Search (CS) Algorithm for the semi-active (SA) suspension system using magneto-rheological (MR) damper. The models are tested with random profile excitations, and the results in the time domain are presented.

\section{Semi-Active (SA) Suspension System}

\section{Quarter Car Model}

In practice, the mechanism for the semi-active (SA) suspension system is remarkably similar to the standard passive suspension system. Nevertheless, in this type of suspension system, there is a spring and controllable damper where the spring part is used to store the energy. In the meantime, the controllable damper is utilised to disperse the energy. The passive spring and the controllable damper are used by some of the semi-active (SA) suspension systems.

The difference between semi-active (SA) suspension and passive suspension systems is their damping mechanism. The semi-active (SA) suspension system can adjust the damping force in real-time, depending on the dynamics of the massed controlled system [16]. Semi-active (SA) suspensions are astonishing among others suspension system because of their negligible demand for power, safety, economical, lightweight, and significantly affecting the vehicle performance.

Since the semi-active (SA) system is based solely on the damping ratio control, the power absorption is restricted to the minimum power needed to adjust the hydraulic orifices or fluid viscosity. The stability in a semi-active (SA) suspension system was assured that the complete system remains dissipative despite the value of the damping ratio for safety purposes. When modifying the suspension system's 
damping ratio, overall body comfort, and road-holding performance will have a significant impact on vehicle performance.

When dissipating energy, the controllable damper usually acts with limited capability to produce a controlled force. The semi-active (SA) system schematic diagram consists of a controllable damper and passive spring as a part of the suspension system shown in Figure 1. The mathematical equations can be described as follows by applying Newton's second law:

$$
\begin{aligned}
& m_{s} \ddot{x}_{s}+F_{d}+k_{s}\left(x_{s}-x_{u}\right)=0 \\
& m_{u} \ddot{x}_{u}-F_{d}-k_{s}\left(x_{s}-x_{u}\right)-k_{t}\left(x_{r}-x_{u}\right)=0
\end{aligned}
$$

where:

$\begin{array}{lll}m_{s} & : & \text { Mass of sprung } \\ m_{u} & : & \text { Mass of unsprung } \\ x_{r} & : & \text { Road disturbance/profile } \\ x_{u} & : & \text { Unsprung mass displacement } \\ x_{s} & : & \text { Sprung mass displacement } \\ k_{s} & : & \text { Stiffness of spring } \\ F_{d} & : & \text { Force of damper }\end{array}$

Table 1 demonstrates the parameters for the quarter car model used in this simulation. The parameters such as sprung mass and unsprung mass are based on the 1:3.5 ratio compare with the original values of quarter car model parameters.

Table 1. The parameter of the quarter car model

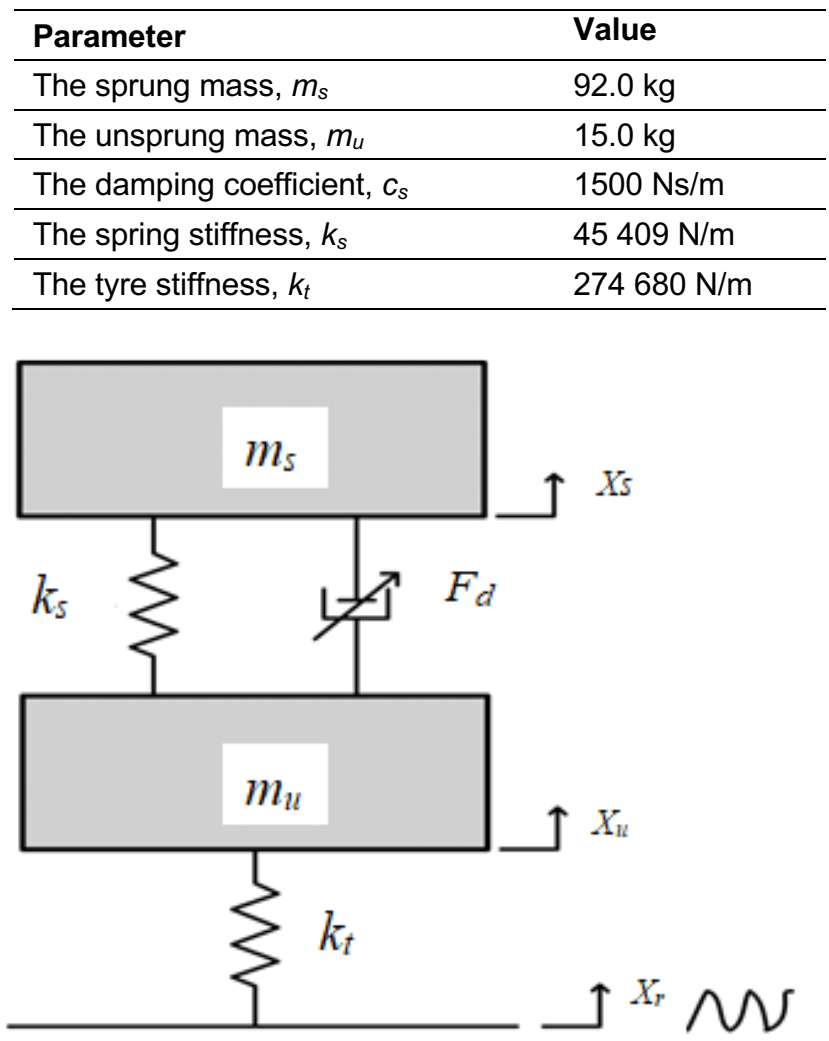

Figure 1. Semi-active (SA) quarter car model

\section{MR Damper Model}

The actuators using in semi-active (SA) suspension systems such as controlled dampers are widely used in the automotive manufacturing industry. The actuators can provide the suspension system with a varying damping coefficient despite being of a similar weight as passive dampers. Automotive 
manufacturers such as Lord, Sachs, and Delphi produce various types of actuators: pneumatic, hydraulic, and magneto-rheological [17].

The MR damper is considered to become one of the most promising supplementary smart materials used for the semi-active (SA) system to control the damping devices [18]. The modelling of the MR damper is one of the main components before controlling the semi-active (SA) suspension system. A controller is required primarily for operating the MR damper in the semi-active (SA) suspension system. As shown in Figure 2, the scope of the controller is to estimate the amount of damping force needed for effective attenuation of discomfort by the MR damper.

The estimate of the required damping force is subsequently converted into the amount of current to be provided to the MR damper for the estimated damping force to be produced. There are generally two types of modelling known as parametric and non-parametric. The parametric modelling includes BoucWenn model, Bingham model, Bingmax model, Modified Bouc-Wenn model, Modified Dahl model, threeelement method, and Modified Lugre Friction. In the meantime, Chebyshev polynomials, Fuzzy Logic, Neural Network, and other methods been considered for non-parametric modelling [19].

The crucial part that needs to be emphasized when implementing the semi-active (SA) with MR damper into the vehicle suspension system is how to develop an effective control strategy in order to resolve the damping constraint. This can be done by reducing the unwanted movement of body vehicles induced by road profile disturbance base on the existing MR damper model. This was due to the unpredicted optimum target force created by the improper design of controllers.

Additionally, it is also essential to conduct a proper design of the control strategy to overcome the damper constraints by providing the same direction between damper velocity and target force. Several works into the utilisation of the MR damper control strategy to enhance the suspension system have been extensively studied through simulation and experimental [12][20][21]. The semi-active (SA) suspension system block diagram is used in this simulation with the optimisation technique and MR damper actuator, as shown in Figure 2.

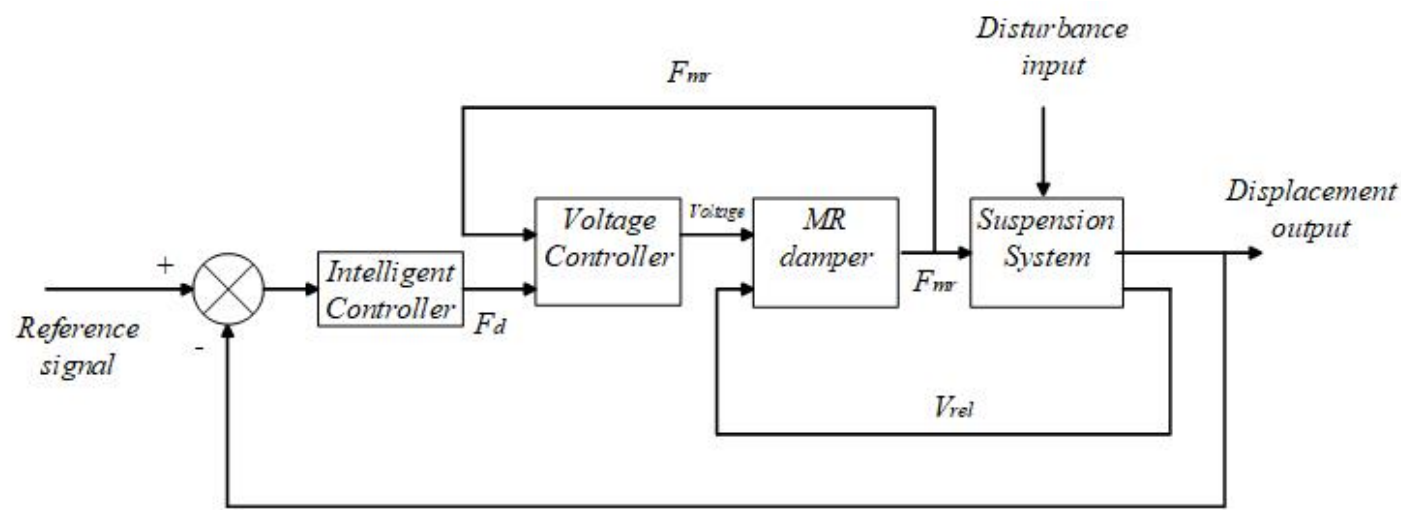

Figure 2. Semi-active (SA) System block diagram

\section{Modelling \& Simulation of Semi-Active (SA) System}

Currently, the problem of parameter tuning for optimisation technique has been resolved using population-based algorithms, a variety of stochastic, nature-inspired, and also computational intelligence algorithms, including fuzzy system and as well as artificial neural networks. The stochastic, populationbased, nature-inspired algorithms are generally impressed by two elements of the natural world.

The optimisation is the process of learning within a given or required time limit to figure out the best 
solution to a problem. There are many well-established methods of optimisation, such as Particle Swarm Optimization, Genetic Algorithm, Firefly Algorithm, and Artificial Bee Colony, used to solve engineering problems by optimising the parameters needed.

The optimisation method such as the Cuckoo Search (CS) Algorithm, has been introduced in this simulation. This optimisation algorithm which was developed by Yang and Deb in 2009, was based on the Cuckoo's behaviour that tend to dump its eggs into random nests [22].

The above said optimisation method as indicated in the control diagram shown in Figure 3 and Figure 4, are used to tune the parameter values of the PID and Skyhook controller for the better optimal values of $K_{P}, K_{l} \& K_{D}$ and $C_{s k y}$. The control diagram for semi-active (SA) by using PID and Skyhook controller were almost similar in the basic structure. The difference was only in the controller part where the PID controller used sprung velocity as the feedback. Meanwhile, in the Skyhook controller, the sprung velocity and relative velocity were used as feedback.

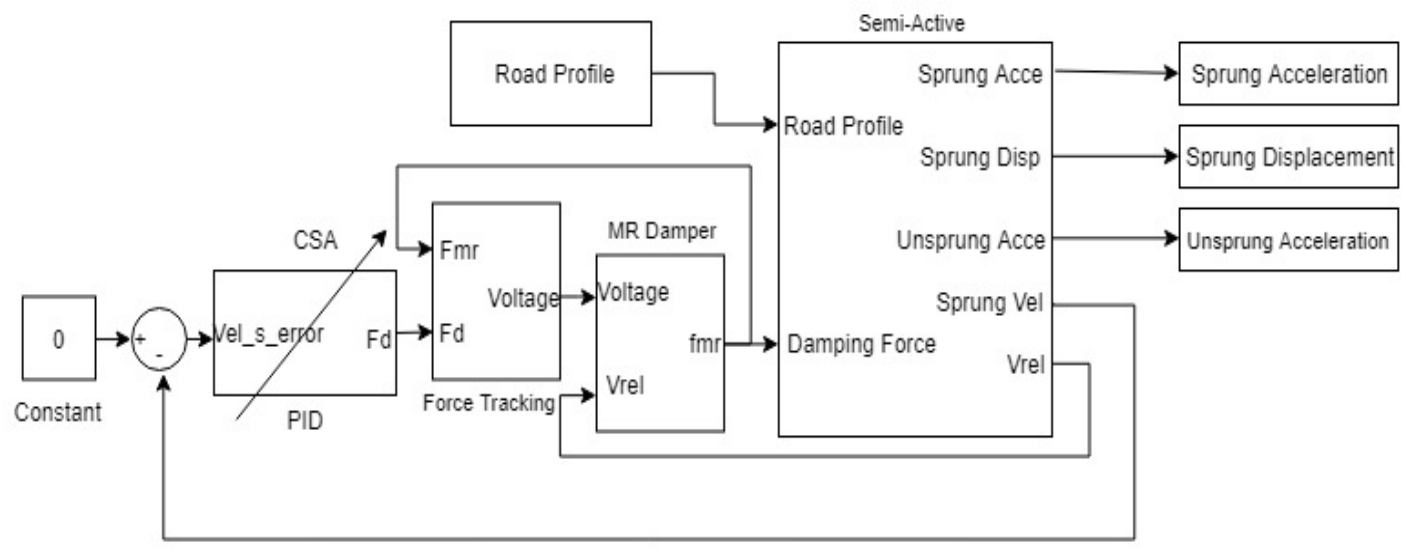

Figure 3. The control diagram of Semi-active (SA) system using PID Controller with CSA

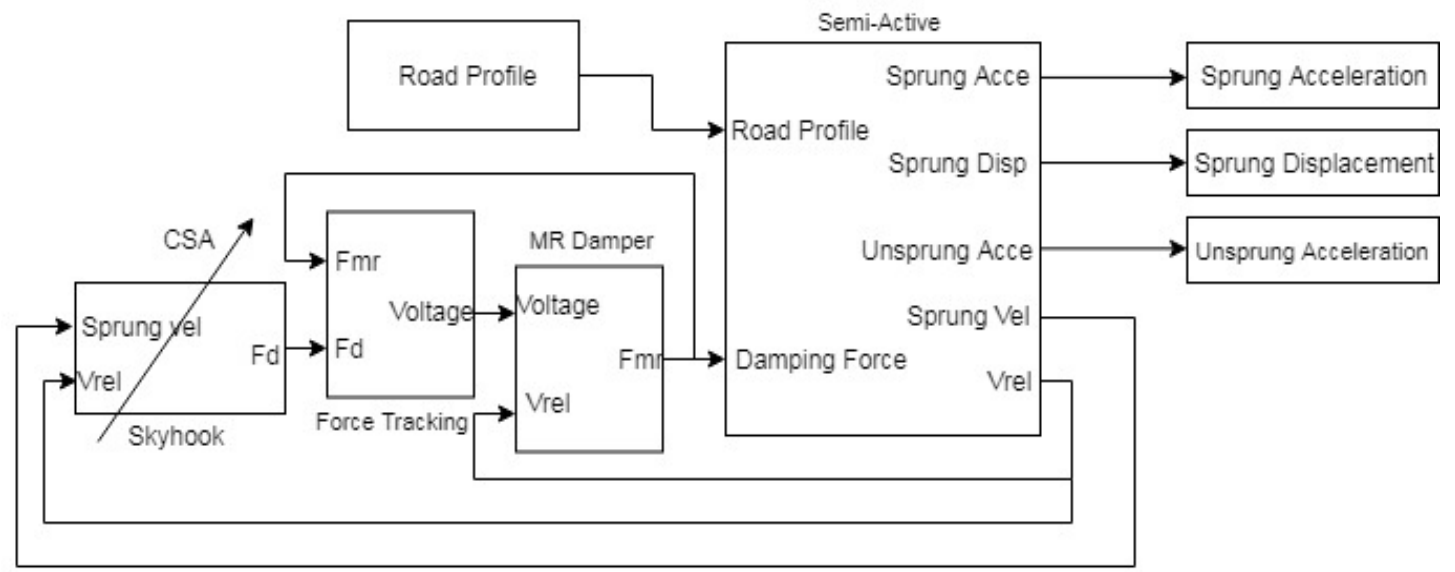

Figure 4. The diagram of the Skyhook controller with CSA for Semi-active (SA) system

\section{Intelligent Controller Development}

Cuckoo Search (CS) Algorithm is an intelligent optimisation technique proposed by Xin-She Yang and Suash Deb in 2009. This algorithm has been influenced by some cuckoo species' obligatory brood parasitism by laying their eggs in the nests of other host birds. Instead, every egg in a nest represents the solution, and a cuckoo egg represents the new solution. The aim is to substitute the weak solution in the nests with the new and potentially better solutions. 
Every nest has one egg, most regularly. It is possible to extend the algorithm to more complicated cases where each nest has multiple eggs representing a set of solutions. In nature, cuckoos are looking on a random path for the nests of host birds. This is indeed a random path since the next step is based only on the current state and the likelihood of a change to the next state [23].

Many researchers highlighted that the details on the optimum design for Cuckoo Search (CS) Algorithm such as initial parameters, initial nests or eggs of host birds, new cuckoo generation by Lévy flights, alien eggs discovery and termination criterion [24][25][26].

The flow chart of the Cuckoo Search (CS) Algorithm shown in Figure 5 summarises the implementation steps in optimising the values of $K_{P}, K_{l} \& K_{D}$. The parameter of Cuckoo Search used in this simulation as tabulated in Table 2.

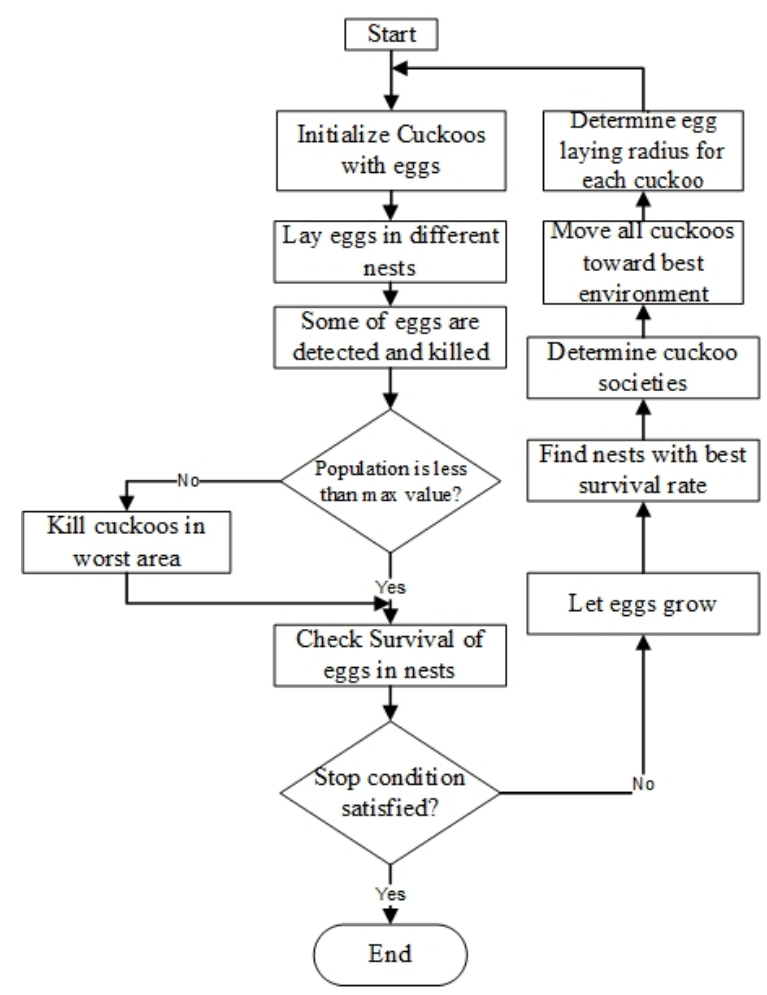

Figure 5. Cuckoo Search (CS) Algorithm Diagram

Table 2. Parameter of the Cuckoo Search (CS) Algorithm

\begin{tabular}{lc}
\hline Parameter & Value \\
\hline Number of the nest $(n)$ & 100 \\
Regeneration number & 30 \\
Step of length $(\theta)$ & 1 \\
Probability of discover $(p a)$ & 0.25 \\
\hline
\end{tabular}

The Cuckoo Search (CS) Algorithm with PID and Skyhook controller were designed by referring to the parameters tabulated in Table 2. The parameter initialisation is required for the Cuckoo Search (CS) Algorithm to operate.

a) PID tuned by Cuckoo Search (CS) Algorithm

PID controller is an impressive control technique, commonly used in process industries as the PID 
controller has proved reliable and robust in regulating process parameters. Several factors have driven industry and research development in choosing a PID controller, such as a low-cost system, easy to manage overall system, flexibility in PID control configuration, and convenient feature [27].

As shown in Figure 6, the PID controller is developed to control the sprung velocity feedback error of the system, so that the proposed controller can estimate the desired force which can be sent to the system. In addition, the PID controller is one of the most useful feedback control structures in the dynamic system and the most remarkable and straightforward contrast to the other controllers [28]. The crucial part in the design of the PID controller is to secure the optimum values of its parameter $\left(K_{P}, K_{l}, K_{D}\right)$. The stability and linearity of the system can be achieved by proposing either several conventional methods or intelligent algorithms.

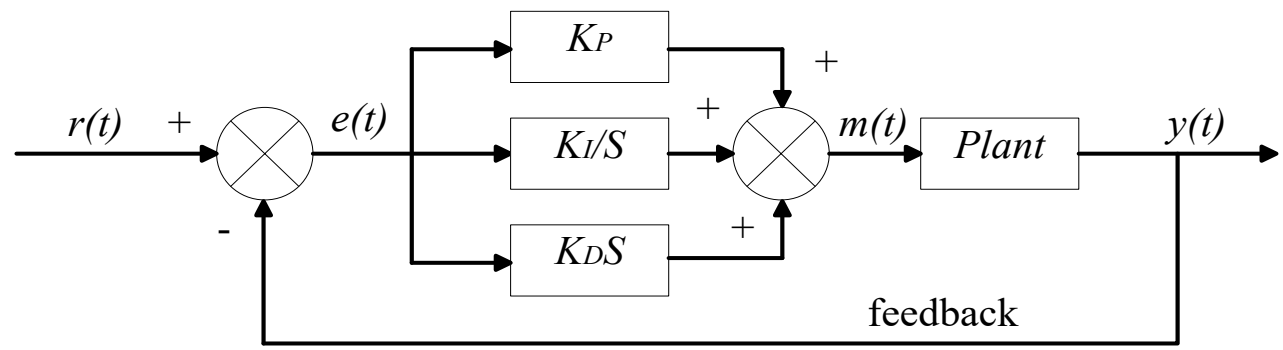

Figure 6. PID controller block diagram

There are conventional methods such as Ziegler Nichols [29], simplex method, heuristic method, and any other relevant methods used for optimal PID tuning in earlier times. The drawbacks of these conventional methods have been widely discussed as it produces large overshoot and settling time as well as its limitation to the linear system only.

Then, intelligent algorithms such as swarm intelligence, fuzzy logic, and other intelligence methods evolved in the optimal control system. The Cuckoo Search (CS) Algorithm is part of the swarm intelligence methods and this algorithm has the advantage of being easier to implement and more convergent in contrast to other meta-heuristic algorithms.

The Cuckoo Search (CS) Algorithm is adapted to tune and obtain the optimum value of $k_{p}, k_{i}$ and $k_{d}$ for the PID controller. Shortly, these values are used to supply the suitable voltage amount for the MR damper in providing the appropriate damper force to the semi-active (SA) suspension system.

\section{b) Skyhook tuned by Cuckoo Search (CS) Algorithm}

The skyhook control is a classical control strategy proposed by Karnopp in 1974 for the vehicle suspension system [10][30]. It was commonly used in both the active suspension and semi-active (SA) suspension control areas. The skyhook control approach is designing the active suspension control so that the chassis is connected to the sky in order to reduce the chassis and axle's vertical oscillations independently of one another. The skyhook model can be represented in Figure 7. The basic equation for skyhook control is given by:

$$
\begin{aligned}
& F_{d}=c_{s k y} \dot{x}_{s} ; \text { if } \quad \dot{x}_{s} v_{r e l}>0 \\
& F_{d}=0 ; \quad \text { if } \quad \dot{x}_{s} v_{r e l}<0
\end{aligned}
$$

The established mathematical equation for the quarter car model with the skyhook control approach is then modelled as follows:

$$
\begin{aligned}
& m_{s} \ddot{x}_{s}+k_{s}\left(x_{s}-x_{u}\right)+c_{s k y} \dot{x}_{s}-\alpha c_{s k y} \dot{x}_{u}=0 \\
& m_{u} \ddot{x}_{u}+k_{s}\left(x_{u}-x_{s}\right)+k_{u}\left(x_{u}-x_{r}\right)+\alpha c_{s k y}\left(\dot{x}_{u}-\dot{x}_{s}\right)=0
\end{aligned}
$$

where: 

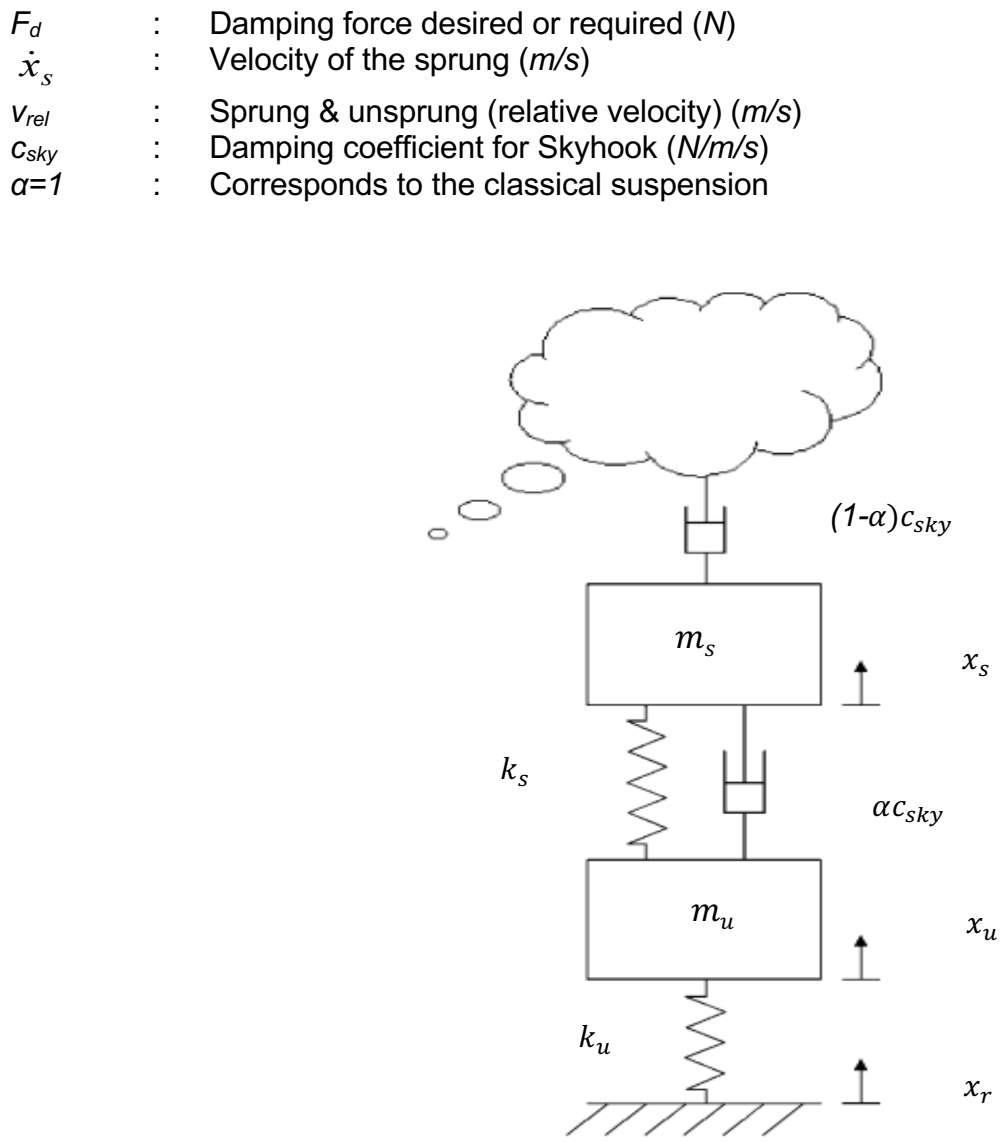

Figure 7. The standard model of the quarter car with the Skyhook control

In real practice, the ideal skyhook technique is hard to realise so it is generally used as an equivalent model. In order to enhance the ride quality, the skyhook control attempts to suppress and reduce the vertical acceleration of the sprung mass by adding an imaginary damper between the sprung mass and the imaginary sky so that the vibration of the sprung mass is dampened by the imaginary damper. As a result, the actual damper in the suspension element attempts to produce the required damping force for the fictitious damper.

All resonant peaks of the sprung mass and unsprung mass must be minimised in order to enhance both the ride quality and the vehicle handling capability. Nevertheless, the skyhook damper cannot operate separately to minimise the resonant peaks simultaneously [31]. Restrictions on the original control of skyhook can be achieved by adopting optimisation approaches in the controller technique.

The Cuckoo Search (CS) Algorithm was introduced to optimise the Skyhook damping coefficient, $c_{s k y}$ in the Skyhook controller scheme. The suitable value of $c_{s k y}$ is selected based on the behaviour of the Cuckoo in searching for the best nest.

\section{MR Damper Modelling}

The MR damper model is one of the crucial mechanisms of the semi-active (SA) suspension system operation. Modified Bouc-Wen model was chosen as the method in modelling the MR damper Lord RD 8040-1 before being applied as an actuator in the semi-active (SA) suspension system. Developing an idealised parametric model for the MR damper under various impact forces and controlling current signals would, therefore, be very decisive.

Modified Bouc-Wen model introduced by Spencer is a proper model that can describe the behaviour of MR fluid [32] [33]. The parameters of the Modified Bouc Wen model as tabulated in Table 3 are required 
to choose properly in order for the MR damper system to perform properly in the semi-active (SA) suspension system. The Equation 7-13 are used in the Modified Bouc Wen model to predict the damper force of the model. The basic equation for the Modified Bouc Wen model can be described as follow:

$$
\begin{gathered}
F_{d}=C_{1} \dot{y}+k_{1}\left(x_{D}-x_{0}\right) \\
\dot{y}=\frac{1}{c_{0}+c_{1}}\left[\alpha z+c_{0} \dot{x}+k_{0}(x-y)\right] \\
\dot{z}=-\gamma|\dot{x}-\dot{y}| z|z|^{n-1}-\beta(\dot{x}-\dot{y})|z|^{n}+A(\dot{x}-\dot{y})
\end{gathered}
$$

where:

$\begin{array}{lll}y & : & \text { Internal displacement } \\ x & : & \text { Damper displacement } \\ x_{0} & \vdots & \text { Initial condition of damper deflection } \\ z & : & \text { Hysteresis restoring force }\end{array}$

Usually, the voltage utilised to the damper is essentially dependant on the current driver from the parameters of the Modified Bouc Wen model and it can be clarified as follows:

$$
\begin{aligned}
& \alpha=\alpha_{a}+\alpha_{b} u \\
& c_{0}=c_{a}+c_{0 b} u \\
& c_{1}=c_{a}+c_{1 b} u
\end{aligned}
$$

where $u$ represents output of the first order filter provided as follows:

$$
\dot{u}=-\mu(u-v)
$$

Table 3. The Parameters of Modified Bouc Wen Model [30]

\begin{tabular}{clcl}
\hline Parameter & \multicolumn{1}{c}{ Value } & Parameter & \multicolumn{1}{c}{ Value } \\
\hline$\alpha_{a}$ & $1921.141 \mathrm{~N} / \mathrm{m}$ & $k_{D 0}$ & $1940.405 \mathrm{~N} / \mathrm{m}$ \\
$\alpha_{b}$ & $5882.51 \mathrm{~N} / \mathrm{N} . \mathrm{N}$ & $k_{D 1}$ & $1.751268 \mathrm{~N} / \mathrm{m}$ \\
$c_{0 a}$ & $651.4718 \mathrm{~N} . \mathrm{s} / \mathrm{m}$ & $A$ & $155.32 \mathrm{~m}^{-1}$ \\
$c_{0 b}$ & $1043.7559 \mathrm{~N} . \mathrm{s} / \mathrm{N} . \mathrm{m}$ & $\beta$ & $36332.07 \mathrm{~m}^{-1}$ \\
$c_{1 a}$ & $2089.263 \mathrm{~N} . \mathrm{s} / \mathrm{m}$ & $\gamma$ & $36332.07 \mathrm{~m}^{-2}$ \\
$c_{1 b}$ & $14384.918 \mathrm{~N} . \mathrm{s} / \mathrm{N} . \mathrm{m}$ & $\eta$ & 60 \\
$x_{0}$ & 0.18 & $n$ & 2 \\
\hline
\end{tabular}

\section{Results and discussion}

The performance of intelligent controllers introduced in this simulation can be investigated by applied sinusoidal road profile $35 \mathrm{~mm}$ excitation with a frequency of $2.6 \mathrm{~Hz}$ to the semi-active (SA) quarter car system. The fitness values against regeneration number for $k_{p}, k_{i}, k_{d} \& c_{s k y}$ as indicated in Figures 8-9 are significant to define the best value for intelligent controller. Table 4 indicates the controller values used in this simulation as the results of the optimisation of PID and skyhook controller with Cuckoo Search (CS) Algorithm. Later, the performance of intelligent PID-CSA and Skyhook-CSA controllers been compared with a passive system in terms of body acceleration, body displacement, and wheel acceleration. 


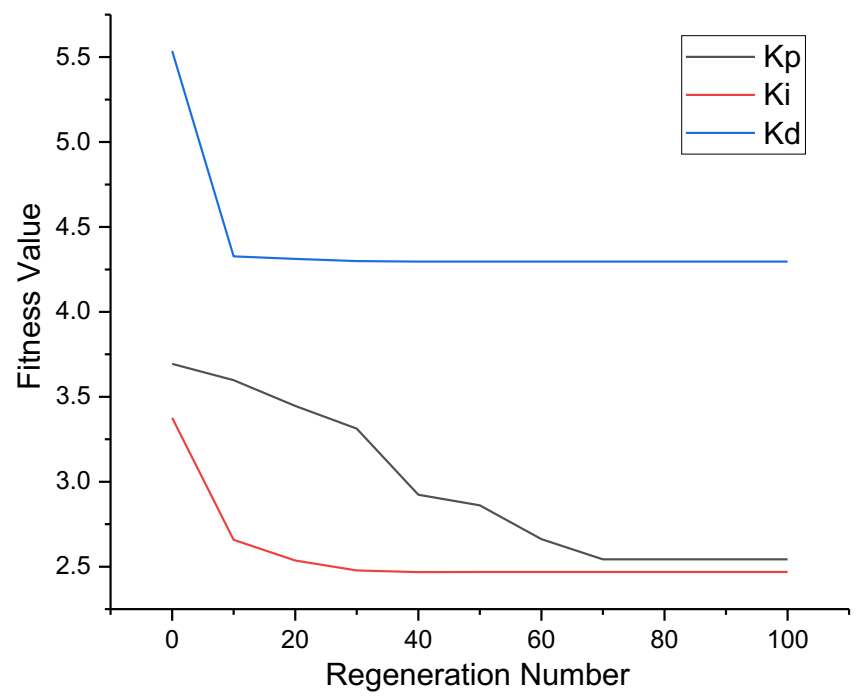

Figure 8. The fitness function against regeneration number for PID Controller

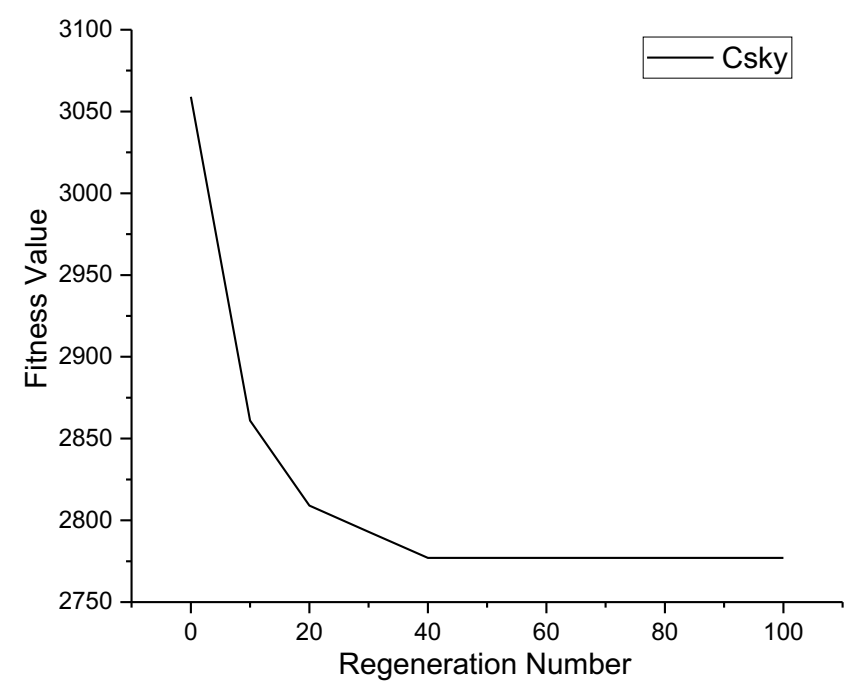

Figure 9. The fitness function against regeneration number for Skyhook Controller

Table 4. Values of Controller Parameter

\begin{tabular}{lcccc}
\hline \multirow{2}{*}{$\begin{array}{c}\text { Quarter Car } \\
\text { System }\end{array}$} & $\boldsymbol{K}_{\boldsymbol{P}}$ & $\boldsymbol{K}_{\boldsymbol{l}}$ & $\boldsymbol{K}_{\boldsymbol{D}}$ & $\boldsymbol{C}_{\text {sky }}$ \\
\cline { 2 - 5 } & 2.5434 & 2.4686 & 4.2962 & - \\
\hline PID-CSA & - & - & - & $2.777 \times 10^{3}$ \\
\hline Skyhook-CSA & - & - & - & - \\
\hline Passive & & &
\end{tabular}

Table 5. MSE and Improvement for Body Acceleration \& Displacement

\begin{tabular}{lcccc}
\hline $\begin{array}{l}\text { Quarter Car } \\
\text { System }\end{array}$ & \multicolumn{2}{c}{ Body Acceleration } & \multicolumn{2}{c}{ Body Displacement } \\
\cline { 2 - 5 } & MSE & Improvement & MSE & $\begin{array}{c}\text { Improvemen } \\
\mathbf{t}\end{array}$ \\
\hline PID-CSA & $2.9599 \times 10^{-5}$ & $25.55 \%$ & 2.2050 & $25.27 \%$ \\
\hline $\begin{array}{l}\text { Skyhook- } \\
\text { CSA }\end{array}$ & $3.8180 \times 10^{-5}$ & $3.96 \%$ & 2.9183 & $1.09 \%$ \\
\hline Passive & $3.9755 \times 10^{-5}$ & - & 2.9505 & - \\
\hline
\end{tabular}


Body acceleration and body displacement as shown in Figure 10-12 are the best indicators in examining controller performance hence identifying the ride comfort for the vehicle occupants. Meanwhile, the wheel acceleration as depicted in Figure 10 indicated that the PID-CSA controller was working well by suppressing the vibration of the suspension system. As a consequence, the PID-CSA attenuates unwanted oscillations for both the vehicle body and wheel part of the vehicle.

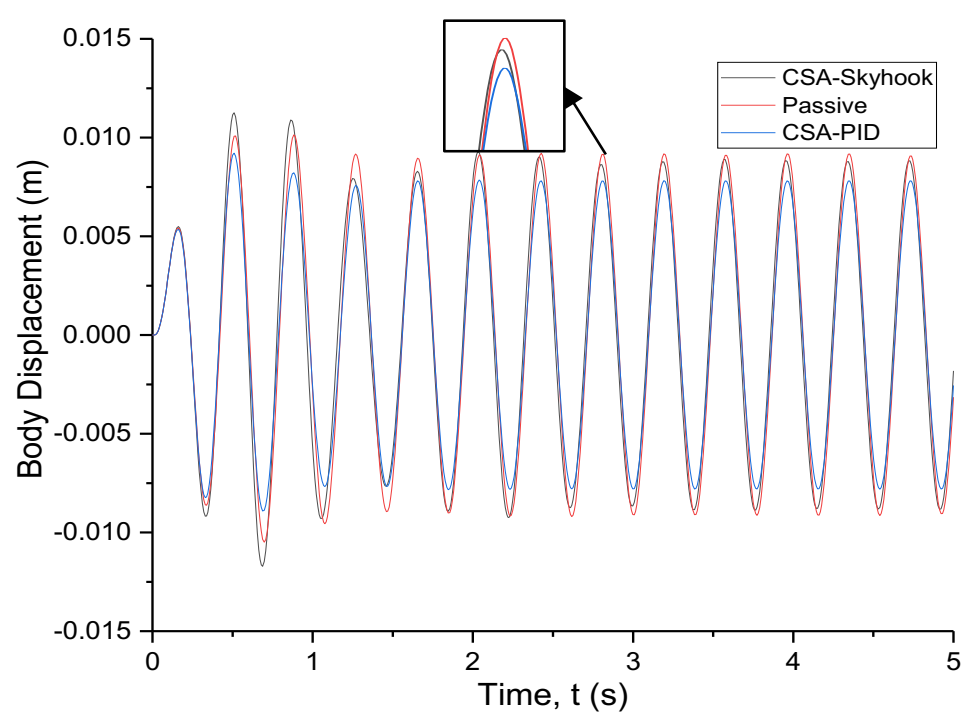

Figure 10. Body Displacement against Time

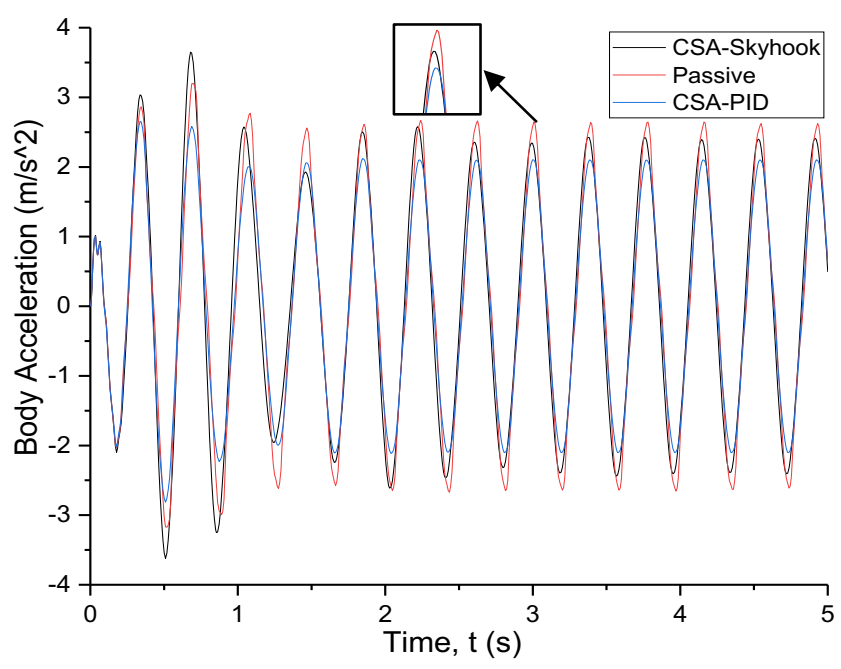

Figure 11. Body Acceleration against Time 


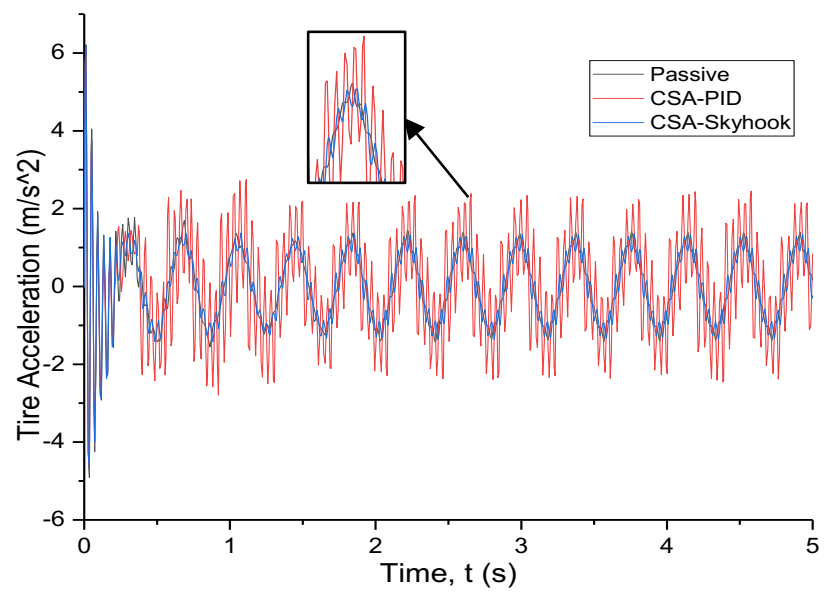

Figure 12. Tire Acceleration against Time

\section{Conclusion}

The proposed PID-CSA and Skyhook-CSA controllers for the semi-active (SA) system were developed using MATLAB Simulink environment. Based on the quarter car simulation results shown in Table 5, the PID-CSA controller has better performance than Skyhook-CSA controller and passive suspension system, with the MSE values of $25.55 \%$ and $25.27 \%$ for body acceleration and body displacement, respectively. It can be inferred that the semi-active (SA) system used by the proposed controllers is capable of enhancing the vehicle's performance in terms of ride comfort and stability as compared to the passive system. It can be observed that CSA outperforms many existing algorithms. The primary explanations are due to a fine balance of randomization and intensification with lesser number of control parameters. Conclusively, for many optimisation problems, CSA is more generic and robust compared with other meta-heuristic algorithms, especially when dealing with engineering problems.

\section{Acknowledgement}

The authors would like to express their gratitude to the Ministry of Higher Education Malaysia (MOHE) and Universiti Teknologi Malaysia (UTM) for funding and providing facilities to conduct this research.

\section{References}

[1] A. S. Yıldız, S. Sivrioğlu, E. Zergeroğlu, and Ş. Çetin, "Nonlinear adaptive control of semi-active MR damper suspension with uncertainties in model parameters," Nonlinear Dynamics, vol. 79, no. 4, pp. 2753-2766, 2015.

[2] G. Hu, Q. Liu, R. Ding, and G. Li, "Vibration control of semi-active suspension system with magnetorheological damper based on hyperbolic tangent model," Advances in Mechanical Engineering, vol. 9, no. 5, pp. 1-15, 2017.

[3] S. A. Abu Bakar, P. M. Samin, H. Jamaluddin, R. A. Rahman, and S. Sulaiman, "Semi active suspension system performance under random road profile excitations," in 2015 International Conference on Computer, Communications, and Control Technology (I4CT), Kuching, Malaysia, 2015, doi: 10.1109/14CT.2015.7219544.

[4] B. A. Negash, W. You, J. Lee, C. Lee, and K. Lee, "Semi-active control of a nonlinear quarter-car model of hyperloop capsule vehicle with Skyhook and Mixed Skyhook-Acceleration Driven Damper controller," Advances in Mechanical Engineering, vol. 13, no. 2, pp. 1-14, 2021.

[5] Ab Talib, M. H., Mat Darus, I. Z., Mohd Samin, P., Mohd Yatim, H., Ardani, M. I., Shaharuddin, N. M. R., \& Hadi, M. S, "Vibration control of semi-active suspension system using PID controller with advanced firefly algorithm and particle swarm optimization," Journal of Ambient Intelligence and Humanized Computing, vol. 12, no. 1, pp. 1119-1137, 2021.

[6] Y. Hu, M. Z. Q. Chen, and Y. Sun, "Comfort-oriented vehicle suspension design with skyhook inerter configuration," Journal of Sound and Vibration, vol. 405, pp. 34-47, 2017.

[7] X. Ma, P. K. Wong, and J. Zhao, "Practical multi-objective control for automotive semi-active suspension system with nonlinear hydraulic adjustable damper," Mechanical Systems and Signal Processing, vol. 117, pp. 667- 
688, 2019.

[8] S. H. Zareh, F. Matbou, and A. A. A. Khayyat, "Experiment of new laboratory prototyped magneto-rheological dampers on a light commercial vehicle using neuro-fuzzy algorithm," Journal of Vibration and Control, vol. 21, no. 15, pp. 3007-3019, 2015.

[9] X. Tang, H. Du, S. Sun, D. Ning, Z. Xing, and W. Li, "Takagi-Sugeno Fuzzy Control for Semi-Active Vehicle Suspension with a Magnetorheological Damper and Experimental Validation," IEEE/ASME Transactions on Mechatronics, vol. 22, no. 1, pp. 291-300, 2017.

[10] P. Krauze, J. Kasprzyk, A. Kozyra, and J. Rzepecki, "Experimental analysis of vibration control algorithms applied for an off-road vehicle with magnetorheological dampers," Journal of Low Frequency Noise, Vibration and Active Control, vol. 37, no. 3, pp. 619-639, 2018.

[11] Z. Ding, F. Zhao, Y. Qin, and C. Tan, "Adaptive neural network control for semi-active vehicle suspensions," Journal of Vibroengineering, vol. 19, no. 4, pp. 2654-2669, 2017.

[12] W. Huang, J. Xu, D. yong Zhu, Y. lei Wu, J. wei Lu, and K. lin Lu, "Semi-active Vibration Control Using a Magneto Rheological (MR) Damper with Particle Swarm Optimization," Arab Journal for Science and Engineering, vol. 40, no. 3, pp. 747-762, 2015.

[13] Talib, M. H. A., \& Darus, I. Z. M., "Self-tuning PID controller with MR damper and hydraulic actuator for suspension system", Proceedings of 5th International Conference on Computational Intelligence, Modelling and Simulation, CIMSim 2013, Seoul, 2013, doi: 10.1109/CIMSim.2013.27.

[14] G. Savaia, S. Formentin, and S. M. Savaresi, "Semi-active suspension control design via Bayesian optimization," IFAC-PapersOnLine, vol. 53, no. 2, pp. 14312-14317, 2020

[15] G. Chen, S. Lv, and J. Dai, "Study on PID control of vehicle semi-active suspension based on genetic algorithm," International Journal of Innovative Computing, Information and Control, vol. 15, no. 3, pp. 1093-1114, 2019.

[16] M. R. Ahmed, A. R. Yusoff, and F. R. M. Romlay, "Adjustable valve semi-active suspension system for passenger car," International Journal Automotive and Mechanical Engineering, vol. 16, no. 2, pp. 6470-6481, 2019.

[17] A. H. Tesfay and V. K. Goel, "Analysis of semi-active vehicle suspension system using airspring and MR damper," IOP Conference Series: Materials Science and Engineering, doi: 10.1088/1757-899X/100/1/012020, 2015.

[18] F. Meng and J. Zhou, "Modeling and Control of a Shear-Valve Mode MR Damper for Semiactive Vehicle Suspension," Mathematical Problems in Engineering, vol. 2019, Article ID 2568185, 2019.

[19] K. S. Arsava and Y. Kim, "Modeling of Magnetorheological Dampers under Various Impact Loads," Shock and Vibration, vol. 2015, Article ID 905186, 2015.

[20] D. Ning, S. Sun, J. Zhang, H. Du, W. Li, and X. Wang, "An active seat suspension design for vibration control of heavy-duty vehicles," Journal of Low Frequenc Noise, Vibration and Active Control, vol. 35, no. 4, pp. 264 278, 2016.

[21] M. H. Ab Talib and I. Z. Mat Darus, "Intelligent fuzzy logic with firefly algorithm and particle swarm optimization for semi-active suspension system using magneto-rheological damper," Journal of Vibration and Control, vol. 23, no. 3, pp. 501-514, 2017.

[22] A. Y. Abdelaziz and E. S. Ali, "Cuckoo Search algorithm based load frequency controller design for nonlinear interconnected power system," Electrical Power and Energy Systems, vol. 73, pp. 632-643, 2015.

[23] M. Mareli and B. Twala, "An adaptive Cuckoo search algorithm for optimisation," Applied Computing and Informatics, vol. 14, no. 2, pp. 107-115, 2018.

[24] A. Kaveh, Cuckoo Search Algorithm, In: A. Kaveh (ed.) Advances in metaheuristic algorithms for optimal design of structures, second edition, Springer International Publishing, pp. 321-351, 2016.

[25] Q. Jin, L. Qi, B. Jiang, and Q. Wang, "Novel improved cuckoo search for PID controller design," Transactions of the Institute of Measurement and Control, vol. 37, no. 6, pp. 721-731, 2015.

[26] M. Yasar, "Optimization of reservoir operation using cuckoo search algorithm: Example of adiguzel dam, Denizli, Turkey," Mathematical Problems in Engineering, vol. 2016, Article ID 1316038, 2016.

[27] N. Mamat, F. Yakub, and S. A. Z. Sheikh Salim, "Analysis of controllers in suppressing the structural building vibration," Malaysian Journal of Fundamental and Applied Sciemces, vol. 15, no. 1, pp. 112-116, 2019.

[28] S. Rajendiran and P. Lakshmi, "Simulation of PID and fuzzy logic controller for integrated seat suspension of a quarter car with driver model for different road profiles," Journal of Mechanical Science and Technology, vol. 30, no. 10, pp. 4565-4570, 2016.

[29] E. K. Anto, J. A. Asumadu, and P. Y. Okyere, "PID control for improving P\&O-MPPT performance of a gridconnected solar PV system with Ziegler-Nichols tuning method," in 2016 IEEE 11th Conference on Industrial Electronics and Applications (ICIEA), Hefei, China, 2016, doi: 10.1109/ICIEA.2016.7603888.

[30] A. H. Mohd Yamin, I. Z. Mat Darus, S. Sahlan, M. H. Ab Talib, and N. S. Mohd Nor, "Intelligent Cuckoo Search Algorithm of Skyhook Controller for Semi-Active Suspension using MR Damper," in 2019 2nd International Conference on Applied Engineering (ICAE), Batam, Indonesia, 2019, doi: 10.1109/ICAE47758.2019.9221732.

[31] K. Hemanth, H. Kumar, and K. V. Gangadharan, "Vertical dynamic analysis of a quarter car suspension system with MR damper," Journal of the Brazilian Society of Mechanical Sciences and Engineering, vol. 39, no. 1, pp. 41-51, 2017. 
[32] Y. Peng, J. Yang, and J. Li, "Parameter identification of modified Bouc-Wen model and analysis of size effect of magnetorheological dampers," Journal of Intelligent Material Systems and Structures, vol. 29, no. 7, pp. 1464-1480, 2018.

[33] C. M. Chang, S. Strano, and M. Terzo, "Modelling of Hysteresis in Vibration Control Systems by means of the Bouc-Wen Model," Shock and Vibration, vol. 2016, Article ID 3424191, 2016. 